\title{
Garaño, S. (2020). Memorias de la prisión política durante el terro- rismo de Estado en la Argentina (1974-1983). Los Polvorines/La Plata/Posadas, Argentina: UNGS/FaHCE-UNLP/UNM.154 pp.
}

Lucas M. Bilbao ${ }^{1}$

«En la prisión todo está ordenado para quebrar al prisionero. Los mecanismos son diversos: presión psicológica, golpes, amenazas, y esa permanente tensión de no saber qué puede ocurrir a cada minuto. Hay que saber esperar, no importa qué, y sobrevivir lo más entero que se pueda».

(Adolfo Pérez Esquivel, ex preso político de la U9 de La Plata, 1996)

Este libro, que resume varios años de investigación, es sin dudas un aporte original entre los estudios de memoria e historia reciente en general y sobre la cárcel política en particular. En las últimas dos décadas se incrementaron los estudios sobre el delito y el castigo en América Latina, ampliándose los saberes vinculados a la conformación de un sistema de cárceles y penitenciarías con características modernas hacia finales del siglo XIX. Esto también tuvo su correlato en el avance de trabajos que ampliaron el conocimiento sobre la legislación competente, los debates en torno al encierro o los actores que conformaron esos espacios (presos, agentes policiales, judiciales, otros) a lo largo del siglo XX. Pese a esto y a la abundante producción que también experimentaron los estudios sobre represión y violencia política en la historia reciente, el libro de Santiago Garaño sistematiza una línea de producción en torno a la prisión política y la violencia carcelaria que ha recibido escasa atención en este campo de estudios. Se trata de «la experiencia de militancia y represión vivida por las miles de personas detenidas por razones políticas que poblaron las prisiones argentinas entre $1974 \mathrm{y}$ 1983». La publicación dentro de la colección Entre los libros de la buena memoria-dedicada a la difusión de investigaciones centradas en temáticas de historia y memoria del pasado reciente- refuerza la calidad de la obra.

La estructura del libro está conformada por una introducción, cuatro capítulos y las conclusiones. En la introducción, y en sintonía con trabajos anteriores, queda de manifiesto el enfoque histórico-antropológico del autor en el que articula equilibradamente el análisis de documentos producidos por las distintas burocracias carcelarias (Servicio Correccional de la provincia de Buenos Aires; Servicio Penitenciario Fede-

${ }^{1}$ Instituto de Geografía, Historia y Ciencias Sociales. Consejo Nacional de Investigaciones Científicas y Técnicas. Universidad Nacional del Centro de la Provincia de Buenos Aires. Contacto: bilbaolucas@gmail.com 
ral; Fuerzas Armadas, entre otras) con un número importante de entrevistas realizadas a ex detenidas y detenidos. Esto le permite reconstruir no solo el funcionamiento administrativo de este engranaje, sino también varios vacíos y silencios que aún están presentes en ciertas narrativas sociales acerca de la cárcel política.

La periodización escogida para el análisis es una decisión acertada. Por un lado, el punto de inicio es 1974 y no el golpe de Estado de 1976, límite bastante usual para este tipo de estudios. Por el otro, el análisis se cierra en 1983 y está ceñido por el fin de la dictadura y la recuperación de la libertad de aquellas/os presas/os políticas/os que aún se hallaban a disposición del Poder Ejecutivo Nacional. Esto permite incorporar al estudio los años en los que se puso en marcha la política represiva dinamizada por grupos paraestatales y centrada en la eliminación del «enemigo interno», al amparo de la «ley antisubversiva» 20.840 y el Estado de sitio, hitos fundamentales que multiplicaron la cantidad de detenidas/os políticas/os a disposición del Poder Ejecutivo Nacional en las cárceles de máxima seguridad.

$\mathrm{Al}$ mismo tiempo, el apartado introductorio plantea dos temas centrales que atraviesan todos los capítulos, articulándose con los núcleos problemáticos de cada uno de ellos. El primero es el lugar de los ex detenidos/as en las narrativas de experiencias traumáticas de represión política. El autor deja en evidencia las dificultades que encontraron desde la década del ochenta hasta hace algunos años, para «convertir ese conocimiento privado en reconocimiento oficial y público». Aparecen en algunas voces los «deberes de memoria» con relación al momento traumático y el recuerdo de las/os compañeras/os que no sobrevivieron y por lo tanto no pueden testimoniar. Vinculado al anterior, el segundo punto pone de relieve el lugar que tuvieron en el sistema represivo estas cárceles que funcionaron en el marco legal. Mientras la historiografía mayormente centró su mirada en las dinámicas represivas clandestinas, Garaño avanza en el estudio y señala que existió «un continuum represivo entre las cárceles y los centros clandestinos de detención», señalando las conexiones, lógicas de funcionamiento, formas y prácticas represivas compartidas en ambos universos.

El primer capítulo -y como plantea el título- está dedicado al análisis de la cárcel de las/os detenidas/os políticas/ os en tanto «espacio de resistencia». La rigidez del sistema activó estrategias y conductas políticas de supervivencia. A partir de algunos relatos de presas/os políticas/os, reconstruye esas formas de resistir, las prácticas, sentidos y representaciones que para ellas/os implicó ese acto. Esto activó la militancia dentro de la cárcel y se estableció a partir del mantenimiento de las estructuras orgánicas de las organizaciones revolucionarias a las que pertenecían los grupos de detenidas/os. Militar fue la forma que encontraron de organizar la praxis políti$\mathrm{ca}$, consolidar identidades o, como rescata la mayoría, «sobrevivir allí adentro». La resistencia se convirtió -según el autor- en un valor moral desde el cual cada detenida/o juzgó -y juzga actualmente- al resto de quienes compartieron esa condición.

En el segundo capítulo estudia un 
caso específico de la dinámica represiva: los pabellones 1 y 2 , llamados «de la muerte», de la Unidad Correccional $\mathrm{N}^{\circ}$ 9 de hombres de La Plata. Allí fueron alojados los detenidos políticos con jerarquía dentro de las organizaciones revolucionarias. De dichos pabellones, entre enero de 1977 y febrero de 1978, fueron sacados varios detenidos políticos para ser asesinados en enfrentamientos fraguados. Pese a las versiones que militares y penitenciarios ofrecieron sobre estos acontecimientos y la estricta vigilancia sobre los represariados en los patios y locutorios, no lograron impugnar los rumores que circularon entre los detenidos. Y les permitió denunciar, a través de los familiares, la existencia de estos pabellones creados para deshacerse de las cúpulas de las principales organizaciones armadas. Esto refuerza la hipótesis del autor de que es necesario conjugar la trama que vinculó la represión llamada «legal» con la clandestina: la Unidad $\mathrm{N}^{\circ} 9$ se convirtió en una de las cárceles que recibió un gran número de «desaparecidos» prevenientes de centros ilegales y que luego fueron «blanqueados» como detenidos políticos.

El siguiente capítulo está dedicado al análisis de Unidad Correccional $\mathrm{N}^{\circ} 2$ de mujeres de Villa Devoto. La entrevista a una ex detenida referente de Montoneros y un conjunto de documentos inéditos elaborados por grupos de presas políticas le permiten al autor mostrar cómo se entrecruzaron las prácticas punitivas del régimen carcelario con las distintas formas de resistencia de estas mujeres. A lo largo del desarrollo se reconstruye la clasificación elaborada por el penal mientras duró su detención, así como la trama organizativa que delinearon al interior de la prisión. Aquí también las detenidas políticas reprodujeron las tareas y responsabilidades que traían de sus organizaciones de base. Siguiendo el relato de quienes estuvieron detenidas allí, la cárcel de Villa Devoto fue una cárcel vidriera, expresión que da título al capítulo. Se trató de una prisión que podía «mostrarse» a los organismos internacionales de derechos humanos que visitaron el país (Amnesty International, 1976; Comité Internacional de la Cruz Roja, 1978; Comisión Interamericana de Derechos Humanos, 1979), a partir de las acusaciones realizadas por exiliadas/os y organizaciones. Esto permitió a las presas hacer públicas las denuncias sobre las violaciones a los derechos humanos en ese lugar.

En el cuarto capítulo, a partir de una sistematización de reglamentos carcelarios y directivas secretas militares conjugados nuevamente con testimonios surgidos de entrevistas se reconstruye el tratamiento penitenciario destinado a las/os detenidas/os por razones políticas. Se evidencia cómo este régimen burocrático (re)pensó las lógicas de funcionamiento y rutinas carcelarias para esta clase de detenidas/os, así como los cambios implementados -fundamentalmente a partir de 1976- cuando quedó integrado a un sistema represivo a escala nacional. Pero también se analiza su contracara: los modos en que las/os detenidas/os lo experimentaron e interpretaron. De esta manera, el autor logra indagar en la construcción de las identidades y lealtades grupales que nacieron durante el período de detención y se vieron reforzadas una vez que fue- 
ron liberadas/os.

Por último, en las conclusiones, se retoman las clasificaciones que el sistema penitenciario elaboró para con las/ os detenidas/os y las resignificaciones que éstas/os hicieron. Esto habilita el tratamiento de un tema aún latente y poco discutido en las memorias carcelarias: la división entre aquellos considerados quebradas/os - «recuperables» en el lenguaje de los carceleros- que cargan con el estigma de la traición y la colaboración con el régimen y aquellos que se mantuvieron inquebrantables $o$, al decir del régimen, «irrecuperables».

Memorias de la prisión política es un estimulante estudio para continuar indagando acerca de las experiencias carcelarias de los años '70. Resta saber más sobre el funcionamiento de las comisarías locales y las «cárceles provinciales» y cómo éstas se integraron a un sistema carcelario mayor, en el marco del plan represivo. Lo mismo acerca de las lógicas de traslados de detenidas/os a lo largo de sus experiencias carcelarias o las presiones y contrapesos de organizaciones, entidades y corporaciones para la liberación las/os mismas/os, entre otros temas. Con todo, este libro se presenta como un valioso aporte para continuar pensando el Estado terrorista y sus engranajes y para reflexionar en torno a cómo un sistema centenario como el penitenciario, pese a ser en apariencias un entramado burocrático preparado y sin fisuras, debió cambiar reglamentos, lógicas y rutinas en función de los objetivos de destrucción psíquica y moral que la última dictadura militar diseñó para las/os detenidas/os políticas/os. 